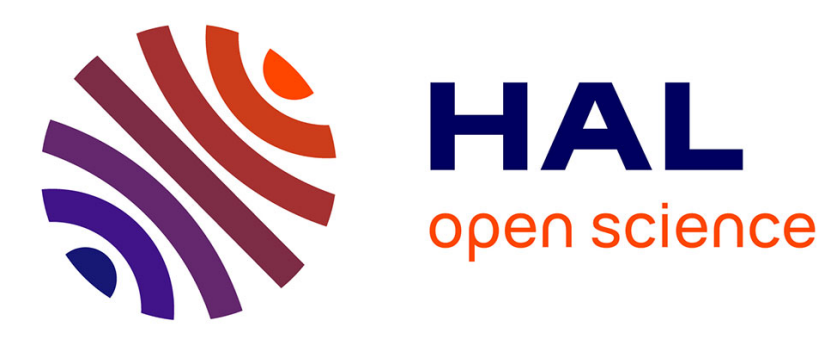

\title{
Cell model of inflammation
}

Jocelyne Franchi, Clarisse Marteau, Claire Crola da Silva, Michèle

Mitterrand, Patrice André, Claudine Kieda

\section{To cite this version:}

Jocelyne Franchi, Clarisse Marteau, Claire Crola da Silva, Michèle Mitterrand, Patrice André, et al.. Cell model of inflammation. Bioscience Reports, 2008, 28 (1), pp.23-32. 10.1042/BSR20070012 . hal-00479292

\section{HAL Id: hal-00479292 \\ https://hal.science/hal-00479292}

Submitted on 30 Apr 2010

HAL is a multi-disciplinary open access archive for the deposit and dissemination of scientific research documents, whether they are published or not. The documents may come from teaching and research institutions in France or abroad, or from public or private research centers.
L'archive ouverte pluridisciplinaire HAL, est destinée au dépôt et à la diffusion de documents scientifiques de niveau recherche, publiés ou non, émanant des établissements d'enseignement et de recherche français ou étrangers, des laboratoires publics ou privés. 


\section{Cell model of inflammation}

Franchi J., Marteau C.*, Crola da Silva C. §, Mitterrand M. §, André P. *, Kieda C. §.

* Laboratoires de Recherche et Développement, LVMH Branche Parfums et Cosmétiques, 45804 Saint Jean de Braye, France.

$\S$ Centre de Biophysique Moléculaire, UPR 4301 CNRS, associated to University of Orleans, affiliated to INSERM, rue Ch. Sadron, 45071 Orléans, France.

Corresponding author: Claudine Kieda $\mathrm{PhD}$

Centre de Biophysique Moléculaire, UPR 4301 CNRS, rue Ch. Sadron, 45071 Orléans, CEDEX 2, France.

Email : kieda@cnrs-orleans.fr

Key words : endothelial cells, keratinocytes, leukocyte adhesion, skin inflammation model

\section{Summary}

Chemical and physical stimuli trigger a cutaneous response by first inducing the main epidermal cells: keratinocytes, to produce specific mediators that are responsible for the initiation of skin inflammation. Activation modulates cell communications namely leukocyte recruitment and blood to skin extravasation through vascular endothelial cells selective barrier. We describe here an in vitro model which takes into account those various steps of human skin inflammation from keratinocyte activation up to the adhesion of leukocytes to dermal capillaries endothelial cells (ECs). Human adult keratinocytes (HAK) were stressed by exposure to ultraviolet-irradiation (UV), or neuropeptides then, the conditioned culture medium was used to mimic the natural micro-environmental conditions for dermal ECs. A relevant skin in vitro model must include appropriate cells from the skin. This is shown here by the selective reactions of dermal ECs as compared to EC lines from distinct origins in terms of leukocytes recruitment, sensitivity to stress, nature of the stress-induced secreted mediators. This simplified model is suitable to the screening of anti-inflammatory molecules whose activity involves the partnership of various skin cells. 


\section{Introduction}

The process by which the skin reacts to an aggression requires the local recruitment of cells and molecules that contribute to the recovery of its integrity. The main epidermal cells, the keratinocytes, when stimulated, initiate the inflammatory response which is characterized by the production of mediators such as IL- 8 and other chemokines, eotaxin, or lectins like Galectin 9 (Akiba et al., 2002; Frink et al., 2007; Igawa et al., 2006; Nickoloff, 2006; Purwar et al., 2007) (Barker et al., 1991; Grone, 2002; Li et al., 1996; Wagner et al., 1999). These, in turn, could act towards the endothelial cells (ECs) of the dermal vessels. It is known that endothelial cells are highly selective in their reactions to the microenvironment and they reflect the organ they belong to as well as its biological state. Therefore it is fundamental for any cellular model of inflammation or invasive process to be able to deal with the endothelial cells from the proper origin. This was proven first by the development and study of endothelial cell lines (Kieda et al., 2002) and this is why we used in this work the skin derived microvascular ECs and the corresponding microenvironment mimicked by human keratinocytes-derived media.

The model proposed here, allowed us to reproduce the various steps of the skin inflammation process. Indeed, activation by keratinocyte mediators such as chemokines and eicosanoids, leads to leukocyte binding via selectins then integrins and other endothelial cells adhesion molecules and their migration through the endothelial cell layer into the subendothelial matrix to reach the site of inflammation (Fagerholm et al., 2006; Farkas et al., 2006; Granger and Kubes, 1994; Springer, 1994). At the molecular level this process is regulated by spatiotemporarily expressed adhesion molecules (Berg et al., 1991), present on both circulating leukocytes and on endothelial cells and in concert with chemokines. A multi-step model of leukocyte adhesion to vascular endothelium was first provided (Butcher and Picker, 1996; Springer, 1994) and is broadly applicable in different tissues, although the details of the signals involved differ. Recirculation begins with blood lymphocytes interacting transiently and reversibly with the vascular endothelium through villous expressed adhesion receptors in a process called rolling. These receptors can be either selectins, which interact with carbohydrate epitopes of addressins, or, less commonly, members of the immunoglobulin (Ig) superfamily, which bind leukocyte integrins (Fagerholm et al., 2006). Activating factors (often chemokines for lymphocytes) bind to specific $G$ protein-coupled receptors on the rolling lymphocytes (Luster, 1998)and trigger rapid activation of integrin receptors on the leukocyte surface. These activated integrins promote arrest and firm adhesion by binding their Ig-family ligands on the endothelium.

In a general way, exposure to ultraviolet B (UV B) irradiation induces acute skin inflammation such as erythema (sunburn), oedema with concomitant modulation of adhesion molecules (Chung et al., 2002; Park et al., 2006; Viac et al., 1997). The resulting inflammation, which includes the release of growth factors, proinflammatory cells and the induction of oxidative DNA damage is known to play a role in aging process, until in cancer development (Heck et al., 2004; Il'yasova et al., 2005; Nishigori et al., 2003; Schmuth et al., 2007; Soter, 1990; Viac et al., 1997; Wang et al., 2002; Wilgus et al., 2003).

Growing experimental evidences indicate that the nervous system can directly modulate the cutaneous inflammatory response by the release of neuropeptides such as Substance P or calcitonin gene-related peptide CGRP (Ansel et al., 1997; Scholzen et al., 1999). The dermal endothelial cells have been described as a target for substance P. After its direct application, they express significant levels of both intercellular adhesion molecule 1 (ICAM 1) and vascular cell adhesion molecule (VCAM) which was accompanied by increased binding to leukocyte (Lindsey et al., 2000). Consequently, the modulation of these various adhesion 
molecules expression could be a good target for anti-inflammatory strategies (Daxecker et al., 2002; Pitzalis et al., 1997; Yuan et al., 2005) which must be directed only to the appropriate endothelial cells, in our case, the dermal microvasculature. In the natural defense reactions, the contribution of endothelial cells (ECs) is enlightened by the endothelium-leukocyte specific process of recognition (Carlos and Harlan, 1994; Kuijpers and Roos, 1993; Schon et al., 2003) that make them targets for cells and molecules (see Kieda, for a review).

As mentioned, because the cells of the vascular endothelia are organospecific (Kieda et al., 2002) (Kieda, 2003) (Dus et al., 2003) they specifically control and mediate inflammation and invasion process. Furthermore, the quiescent endothelium maintains a status quo, but undergoes a series of metabolic changes in inflammation : endothelial cell activation (ECA).

ECs respond to a variety of stimuli, including pro-inflammatory cytokines IL1 (interleukin1), TNF $\alpha$ (tumor necrosis factor), AGEs (advanced glycation end products), oxidized lipids and environmental conditions such as chemical (oxidative) and physical (shear mainly) stress.

ECs exposed to cytokines, which mediate the inflammatory response, undergo quantitative changes in the synthesis of certain gene products (proteins) that, in turn, endow ECs with their new capacities for performing new functions (Dus et al., 2003; Kieda and Dus, 2003). The five main changes associated with ECA are a loss of vascular integrity, production of EC adhesion molecules, the secretion of cytokines, prothrombotic changes and increased production of lymphocyte adhesion molecule ligands. These phenotypic changes that make up endothelial activation amplify local inflammation. Endothelial activation is also critical in physiological situations such as the accumulated effects of micro inflammatory states which contribute to the aging process (Bosset et al., 2003; Giacomoni and Rein, 2001; Hase et al., 2000) as particularly shown in the skin (Conway et al., 2007; Giacomoni and Rein, 2001; Homey et al., 2002; Le et al., 2004; Scholzen et al., 2007).

Thus, the structural and functional integrity of the barrier formed by the endothelium is essential for the maintenance of blood vessel wall homeostasis.

The ECs select circulating cells for recruitment to inflammatory site and skin-infiltrating $\mathrm{T}$ cells appear to be central in controlling the initiation and maintenance of skin inflammation (Campbell and Butcher, 2002; Hunger et al., 1999; von Andrian and Mackay, 2000). Moreover, endothelial barrier display organ and vessel type distinct characters which helps to explain the biological sorting that they achieve as shown in a previous work by establishing phenotype-stabilized endothelial cell lines from different tissue origins (Kieda et al., 2002).

Existing models are limited because they deal with one cell type response and /or with nonrelevant origin cell cultures. These have brought interesting but partial information about keratinocytes specific inflammation induced factors and their implication on later events (Bruynzeel et al., 1997; Choi et al., 2004; Grandjean-Laquerriere et al., 2003). Despite the highly informative data obtained by direct and general activation of adhesion molecules described in most studies with umbilical cord derived ECs (Bevilacqua, 1993), the endothelial reaction has been proven to be organo selective and microenvironment-dependent as illustrated by the skin recruitment of cutaneous lymphocyte antigen positive T (CLA+T) lymphocytes (Berg et al., 1991; Hunger et al., 1999). This is why, our organospecificity-based model is potentially able to produce fundamental and biologically relevant new informations about invasion mechanisms. Hence, knowledge of the molecular mechanisms by which leukocytes are recruited to the skin could provide promising targets for the development of new anti-inflammatory molecules able to modulate the process of keratinocyte initiated inflammation.

Moreover, our model which combines different skin representative cells and CLA+T lymphocytes, allows the study of their selective reactions and contributes to validate the endothelial cell organo-specificity hypothesis. 


\section{Materials and Methods}

Preparation of human keratinocytes and cell culture.

Adult human keratinocytes (HAK) were obtained after the excision of skin during plastic surgery from non related healthy donors. Skin sample $(0.5 \mathrm{~mm})$ prepared with a dermatome was floated on a $0.05 \%$ solution of trypsin (Gibco, France) for $30 \mathrm{~min}$ at $37^{\circ} \mathrm{C}$. The epidermis was separated from the remaining dermis and an epidermal cell suspension was obtained by pipetting and filtering through sterile gaze.

The resulting epidermal cells were plated at high density in $100 \mathrm{~cm}^{2}$ dishes at $37^{\circ} \mathrm{C}$ in a humidified, $5 \% \mathrm{CO}_{2}$ incubator. Monolayer cultures of keratinocytes were established in the serum-free medium MCDB 153 (KBM, BioWhittaker, Belgium) supplemented with $0.5 \mu \mathrm{g}$ $\mathrm{mL}^{-1}$ hydrocortisone, $5 \mu \mathrm{g} \mathrm{mL}^{-1}$ insulin, $10 \mathrm{ng} \mathrm{mL}^{-1}$ epidermal growth factor (EGF) and $56 \mu \mathrm{g}$ $\mathrm{mL}^{-1}$ bovine pituitary extract (Boyce and Ham, 1983).

\section{Preparation and culture of immortalized human microvascular endothelial cell lines}

Microvascular ECs were isolated from surgical specimens by the technique of Bizouarne (Bizouarne et al., 1993a; Bizouarne et al., 1993b)(for mouse endothelial cells) adapted for use with human endothelial cell lines, they were immortalised and stabilised as described (Kieda, CNRS patent 99-19169, (Kieda et al., 2002). The cell lines used were:

HSkMEC.1: human skin microvascular endothelial cells, immortalised cells from normal skin.

HPLNEC.B3 : human high endothelial cells from high endothelial venules from a cervical lymph node of a patient with Hodgkin's lymphoma.

HBrMEC : human brain microvascular endothelial cells, immortalised from a biopsy of normal brain tissue.

ECs were cultured in OptiMEM 1 with Glutamax-I (Invitrogen, U.K.) supplemented with 3\% FBS (foetal bovine serum) from Biochrom KG, Berlin (Germany), $40 \mathrm{mg} / \mathrm{ml}$ Gentamycin (Panpharma, Fougères, France) and $0,5 \mathrm{mg} / \mathrm{ml}$ Fungizone (Gibco, United Kingdom). ECs were passaged using 0.05\%/0.02\% w/v Trypsin/EDTA solution (Biochrom AG, Berlin, Germany).

The experiments were performed between passage 3 to 12 .

\section{Culture of human leukocytes}

Human leukemic cell lines were used in adhesion experiments:

CEMT4 - leukemic CD4 ${ }^{+} \mathrm{T}$ cell line, was provided by Dr P. Olivier, Institut Pasteur, Paris, France [Hunger, $1999 \# 16]$.

$\underline{\text { Stress generation in HAK cultures using UV B irradiation, substance P and CGRP }}$

Subconfluent cultures of HAK were rinsed twice with phosphate-buffered saline (PBS).

UV B irradiation . cells were irradiated in a film of PBS using a BioSun irradiator (Vilbert Lourmat, Marne-la-Vallée, France). They were exposed to10 $\mathrm{mJ} \cdot \mathrm{cm}^{2}(312 \mathrm{~nm})$. This is a non cytotoxic dose, as determined by counting the number of cells remaining.

Stimulation with substance $\mathrm{P}$ and CGRP. HAK were incubated with $10^{-7} \mathrm{M}$ of each neuropeptide for 24 hours or with $100 \mu \mathrm{M} \mathrm{H}_{2} \mathrm{O}_{2}$ (from Sigma, France) for 1 hour, washed and placed in normal medium for 16 hours.

Control HAK were not irradiated or incubated with stimulators.

CGRP and substance P were obtained from Sigma, France. 


\section{$\underline{\text { Anti inflammatory assessment }}$}

The conditioned medium from stressed keratinocytes was collected and added to cultures of endothelial cell in order to activate them mimicking the process of inflammation. This newly created microenvironment is used to reproduce physiological attacked skin in which the endothelial cells respond by producing a range of adhesion molecules to recruit competent leukocytes. Stressed keratinocytes were incubated with the anti-inflammatory molecules $10^{-7}$ $\alpha$-MSH (melanin stimulating hormone), $10^{-6}$ dexamethasone or $10^{-6} \mathrm{M}$ indomethacin for $48 \mathrm{~h}$ to modulate their response. The adhesion-inhibiting properties of the cells were then assessed by an in vitro assay (see below).

Quantitative assay of leukocyte (CEMT4) adhesion to endothelial cells

\section{Labeling leukocytes with PKH26 GL}

CEMT4 cells were labeled with the red fluorochrome PKH26-GL (Paul Karl Horan 26 general labeling) according to the manufacturer's recommendations (Molecular Probes, purchased from Sigma, France), as adapted by Kieda [Kieda, 2002 \#9]. Cells were incubated with the label for 2-3 min at $37^{\circ} \mathrm{C}$ with gentle mixing, washed with PBS (phosphate buffered saline), and suspended in PBS $\left(10^{6}\right.$ cells $\left./ \mathrm{mL}\right)$.

\section{Adhesion of leukocytes to endothelial cells}

Endothelial cells in complete OptiMEM medium were plated out in 24-well tissue culture plates (Falcon, Becton Dickinson, France) $\left(0.75 \times 10^{5}\right.$ cells in $400 \mu \mathrm{L}$ per well) $24 \mathrm{~h}$ before the test. Just before the test, the cell monolayers were washed with PBS-BSA (bovine serum albumin) and kept at $4^{\circ} \mathrm{C}$. CEMT4 cells were layered over the EC monolayers at a ratio of 5: 1 and the plates incubated for 20 min at $4{ }^{\circ} \mathrm{C}$. Non-adhering cells were removed by two gentle washings with PBS. Endothelial cells and adhering cells were detached from the tissue culture plate by a short incubation with PBS containing 0.02\% EDTA (Ethylene diamine tetra acetate) (w/v), washed and analyzed by flow cytometry (FACSort Becton Dickinson, Sunnyvale, CA, USA). Data were recorded for 5000 events, using CellQuest ${ }^{\circledR}$ software. The percentages of each cell type in the samples were calculated using the CellQuest $^{\circledR}$ software. Results are presented as the number of adherent cells per EC counted at the end of the adhesion step. Remark : the final counts can be not related to the initial 5 to 1 ratio because of the differential reactivity of some ECs among the whole population and the activation subsequent to early recognition (non published observations). The presented data were all analyzed by the Student's t test.

\section{Adhesion of leukocytes to keratinocytes}

The direct adhesion of leukocytes to keratinocytes was assessed by the same technique.

Detection of mediators in conditioned medium from stressed keratinocytes.

Aliquots of stressed keratinocyte-conditioned medium were stored at $-70{ }^{\circ} \mathrm{C}$ until used to assay IL-8 (interleukin-8), s-ICAM-1 (soluble intercellular adhesion molecule) and IL-7 (interleukin-7) using enzyme-linked immunoabsorbent assays (ELISA) kits (R\&D, Abingdon, UK), according to the manufacturers' instructions. 


\section{Results}

\section{Cell model of skin inflammation}

The intercellular cooperations involved in skin inflammation could be estimated in vitro by stressing keratinocytes, incubating dermal microvascular endothelial cells with the resulting conditioned medium, and then measuring the capacity and specificity of the adhesion properties of these endothelial cells (see Figure 1A).

The results of the adhesion assays were analyzed by flow cytometry based on the forward and side scattered light differences between EC and lymphocytes. Furthermore, the lymphoid cells could be identified by their fluorescence due to PKH 26 GL labeling producing a bright fluorescence (FL2). Figure 1B illustrates the increase of lymphocytes (FL2 positive cells in the upper left quadrant) able to adhere to endothelial cells (non fluorescent, lower left quadrant) upon stimulation by a given stress. In the subsequent experiments, data express the number of leukocytes adhering per on endothelial cell calculated from the dot plot analyses as shown above and computed in histograms.

$\underline{\text { Inflammation induction assay }}$

\section{Validation of the inflammation model}

Keratinocytes exposed to UV-light released into the medium, mediators that activated endothelial cells, in terms of increased adhesion capacity as shown here for one representative experiment in triplicate (Figure 2A). This response was modulated by anti-inflammatory molecules such as $\alpha-\mathrm{MSH}$, which is known to protect the skin from UV irradiation (Eves et al., 2006; Luger et al., 1997; Oktar and Alican, 2002; Scholzen et al., 1999; Scholzen et al., 2007).

Moreover, the keratinocytes responded to stress also by increasing their capacity to bind leukocytes (Figure 2B). In the frame of this type of experiments, $\alpha$-MSH reduced totally the $\mathrm{UV}$-induced increase of the adhesion capacity towards CEMT4 lymphocytes when added to the keratinocytes. This reduction is almost total for endothelial cells stimulation. This is quite significant because $\alpha$-MSH by itself did never modify the adhesion properties of either keratinocytes or endothelial cells (data not shown). This is particularly important in terms of anti UV-induced inflammation since it was shown by Scholzen that the termination of inflammatory process is due to dermal endothelial cells proteolytic enzymes (ACE) (Scholzen et al., 2007).

This indicates that the system mimics the physiological situation in which inflamed tissues are infiltrated by leukocytes. Conversely, $\alpha$-MSH reduced the response of both endothelial cells and keratinocytes, confirming the validity of the proposed assay.

\section{$\underline{\text { Organ-selectivity of endothelial cells: distinct adhesion/activation patterns }}$}

The studies on the adhesion process were done to refine the in vitro model in the light of knowledge of endothelial cell selectivity. They have shown that it is a function of the endothelial cell type and tissue origin (Kieda et al., 2002); our data for one representative experiment (Figure 3 ) indicate that it is also a function of the biological stimulus encountered by the ECs. Thus confirming that the endothelial cells are reacting differently according to the organ they belong to and reflect the biological and the microenvironmental state. 
Under resting conditions, the CEMT4 cells adhered preferentially to endothelial cells derived from the skin and especially, from brain rather than those from the peripheral lymph nodes. But upon activation by keratinocyte derived conditioned medium by substance $\mathrm{P}$ and to a lesser extent by UVB, CEMT4 cells adhered up to three times better to skin-derived endothelial cells as compared to a two fold increase for the brain-derived EC. Even though the basic adhesion value due to brain derived EC was higher than skin derived ECs, activation enhanced the differential behavior. Treatment of ECs with medium from keratinocytes subjected to UV irradiation increased the adhesion ability of both HSkMEC and HBrMEC to a lesser extent. The medium from keratinocytes activated with CGRP did not increase the adhesion capacity of these ECs.

Organo specific reactivity of the endothelial cells was pointed out by the data from this experiment because lymph node-derived ECs (HPLNEC.B3) were not sensitized by keratinocyte-conditioned medium when the stress was produced by UV irradiation or substance P. They respond to medium from CGRP-treated keratinocytes differently, with a very small increase in their adhesion properties.

Modulation of dermal microvascular endothelial cell activity under inflammatory conditions.

\section{Inflammatory conditions produced by stressed keratinocytes}

We tested the validity of our model to reproduce the inflammatory cascade induced by UVB irradiation, substance P or CGRP as described by (Scholzen et al., 1999; Soter, 1990) and its modulation by potent anti-inflammatory molecules.

Exposure to ultraviolet B (UVB) irradiation induces acute skin inflammation such as erythema (sunburn), oedema. Inflammation, which includes the release of growth factors, proinflammatory cells and the induction of oxidative DNA damages, is known to play a role in aging process and cancer development (Nishigori et al., 2003; Soter, 1990; Wilgus et al., 2003). The neurologic system directly modulates inflammatory cutaneous response by the release of neuropeptides such as Substance P or CGRP (Ansel et al., 1997; Scholzen et al., 1999). Consequently, keratinocytes were stressed by exposure to UVB irradiation or by incubation with Substance P or CGRP.

Endothelial cells are proposed to be a target: by direct application of substance P they express significant levels of both intercellular adhesion molecule-1 (ICAM-1) and vascular cell adhesion molecule (VCAM) which was accompanied by increased binding to leukocyte (Lindsey et al., 2000).

The capacity of the conditioned medium from these stressed keratinocytes to modulate the properties of dermal endothelial cell was tested upon leukocytes adhesion as a result of the inflammatory cellular recruitment in an organ restricted way (Berg et al., 1991; Campbell and Butcher, 2002; Hunger et al., 1999; Kieda, 2003; Kieda et al., 2002).

Among the main mediators which are known to be released by keratinocytes as IL-1,IL-6, IL-

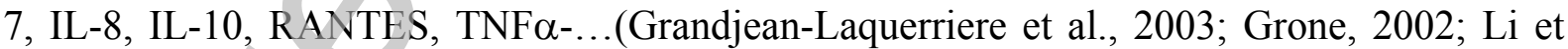
al., 1996; Wagner et al., 1999) we focused on IL-8 (Zhang and Chen, 2002), RANTES (Ley, 2003), IL-7 (Dus et al., 2003), s-ICAM-1 (Witkowska and Borawska, 2004) for their direct implication in endothelial cell biology .

The data concerning the behavior of these above mentioned mediators upon keratinocyte stress by UVB and substance P are presented in table 1. Under the same keratinocyte stress conditions we followed the effect of mediator release by keratinocytes on endothelial cell activation. Data expressing the recruitment capacity in terms of number of leukocytes adhering per one endothelial cell are given in table 2.

Taking into account the work by Middleton et al. (1995) on ICAM-1 expression on keratinocytes (Middleton and Norris, 1995) which shows an important donor variability we performed the studies on several individuals. In our hands, despite the observed inter donor 
differences, the applied stress caused a repetitive and significant increase of the amount of released mediators along with an increase in the recruitment of lymphoid cells.

IL-8 and s-ICAM appeared to be the most sensitive of the mediators studied.

This demonstrates that limiting the evaluation of inflammation to the measurement of the keratinocyte responses is not sufficient, the influence of the micro-environment on dermal microcapillaries must also be assessed. It was done here by the use of organ-specific endothelial cells by which method it was possible to evaluate the potential of antiinflammatory molecules.

Effect of anti-inflammatory molecules on the activation of dermal microvascular endothelial cells

Potent anti-inflammatory molecules such as $\alpha$-MSH, indomethacin, dexamethasone were used to check the endothelial cell model of inflammation and to validate its potential for estimating the anti-inflammatory (or pro-inflammatory) properties of molecules. Keratinocytes were irradiated with UV or incubated with substance P, and then incubated with the test molecules for 2 days. The resulting medium was then tested for its ability to modulate the properties of dermal endothelial cells (leukocytes adhesion and/or adhesion molecule production).

The data indicate that the conditioned medium from keratinocytes incubated with stimulant plus anti-inflammatory agent decrease the adhesion capacity of dermal endothelial cells as much as medium from keratinocytes treated with anti-inflammatory agent alone (figure 4). Dexamethasone clearly inhibited the UV-induced production of keratinocyte factors, but did not block activation by substance $P$.

The endothelial model is an effective method of assessing inflammation and the effects of anti-inflammatory molecules; it is selective and reflects biologically significant effects. We therefore believe it can be used to screen potentially therapeutic molecules and drugs. 


\section{Discussion}

The specific immunologically active products generated by keratinocytes in response to environmental stress, including physical stimuli such as UV light and endogenous signals such as neuropeptides initiate the amplification of cutaneous inflammation (Barker et al., 1991; Bizouarne et al., 1993b; Boyce and Ham, 1983; Purwar et al., 2007; Scholzen et al., 2007). Our in vitro data demonstrate that keratinocytes can interact with infiltrating immune cells by releasing pro-inflammatory cytokines (Table 1) or via intercellular adhesion molecules leading to modified adhesion properties (Table 2). Keratinocytes function as transducers of environmental signals, converting exogenous stimuli into the signal molecules implicated in the activation of dermal endothelial cells, and hence the recruitment and sequestration of specific leukocytes.

Their highly specific reactions indicated that the significance of such an in vitro model requires the use of appropriate cells from the skin (Kieda, 2003; Kieda et al., 2002).

This model is suitable for studying endothelial cell-mediated leukocyte recruitment and the modulation of the inflammatory process by keratinocyte activity. It illustrates the early steps of leukocyte movement from the blood into the peripheral tissues. Quantitative measurements of adhesion made it possible to assess the biological effects of immunomodulatory molecules. A growing body of experimental evidence suggests that UV-induced skin inflammation is influenced by the sensory nervous system acting via the neuroendocrine system, involving a complex network of cytokines, chemokines, neuropeptides, and neuropeptide-degrading enzymes including neuroendocrine hormones like the proopiomelanocortic peptides (POMC) and particularly, $\alpha \mathrm{MSH} . \alpha \mathrm{MSH}$ is released by stimulated epidermal cells including keratinocytes, Langerhans cells, and melanocytes, as well as immunocompetent cells. It has recently been recognized as a potent immunomodulator that inhibits the production and activity of immunoregulatory and proinflammatory cytokines. Since $\alpha \mathrm{MSH}$ modulates the NFkB transcription factor, it may well affect the very early steps of the inflammation cascade (Luger et al., 1998; Luger et al., 1997; Luger et al., 2003) as confirmed by this work (figure 2) and preliminary data showing that it reduces the expression of E selectin on dermal ECs (not shown).

This model based on HAK, HSkMEC.1 and CEMT4 human cells (figure 1A) can be used as a tool for studies in skin biology. It is suitable for evaluating the anti-inflammatory properties of potential topically active molecules and should help in the search for new anti-inflammatory therapies (figure 4). Hence, this could lead to a better understanding of pro-inflammatory mechanisms. This cell model demonstrates that limiting the evaluation of inflammatory responses to that of keratinocytes is not sufficient, since a major effect is the resulting recruitment of competent leukocytes by adhesion to dermal microcapillaries. Any estimation of the amplitude of an inflammatory process therefore requires a study of the microenvironmental conditions that influence dermal microcapillaries. This is exactly what our organ-specific endothelial cell model provides.

The modulation of inflammation by the release of soluble factors (cytokines, soluble adhesion molecules) such as IL-7 and s-ICAM-1 appears to be quite significant, as indicated by the influence of keratinocyte-conditioned medium on endothelial cells. It increased the adhesion of leukocytes to endothelial cells (Table 2). Treatment of keratinocytes with antiinflammatory molecules reduced the capacity of the conditioned medium to induce adhesion. Consequently, the model described here is valid for studying inflammatory reactions by assessing the adhesion/recruitment of leukocytes to endothelial cells. Our data also emphasize the need to deal with appropriate organ-selective endothelial cells (i.e. dermal), the importance of microenvironmental cross-talk between keratinocytes and microcapillary endothelial cells (figure 3) and the importance of the interaction between appropriated 
selecting endothelial cells and responsive leukocytes for studying tissue invasion (Nickoloff, 2006).

Especially, one has to take into that, in the presence of the appropriate migratory signals, the leukocyte migrate across the endothelium into tissue, where tissue-associated chemokine gradients also direct the final localisation.

Consequently, the longer-term goals of this work are to understand the skin reactions that occur in response to damage and aging and to design new active specific molecules, taking into account the organ-specific production and presentation of chemokines (Kunkel and Butcher, 2002) which means, for skin-related studies, the fractalkine(Echigo et al., 2004; Hasegawa et al., 2005) (Sugaya et al., 2003) and the skin-derived CCL27 (Chen et al., 2006; Hayakawa et al., 2005; Homey et al., 2002; Homey et al., 2007; Moed et al., 2004)].

\section{Acknowledgements:}

This work was supported by grants from INSERM-progress (CK), the Jerôme Lejeune foundation $(\mathrm{CK})$ and LVMH.

CK is Research Director at CNRS, CC is an ANRT-CIFRE fellow, MM is an AI at CNRS 


\section{Tables :}

\section{Keratinocyte treatments}

UVBs $10 \mathrm{~mJ} / \mathrm{cm}^{2}$

$\mathrm{X} /$ control $(\%) \mathrm{n}$
minima maxima

Substance P 10-7 M

$$
\begin{aligned}
& \mathrm{X} / \text { control }(\%) \\
& \text { minima maxima }
\end{aligned}
$$

$\begin{array}{lcrlccc}\text { IL-8 } & 50^{*} & 408^{*} & 4 & 38^{*} & 386^{*} & 3 \\ \boldsymbol{S}-\boldsymbol{I C A M} & 362^{*} & 1218^{*} & 2 & \text { nd } & \text { nd } & \\ \text { RANTES } & 28 & 482^{*} & 3 & \text { nd } & \text { nd } \\ \text { IL-7 } & 0 & 303 * & 3 & \text { nd } & \text { nd }\end{array}$

Table 1: Secreted mediators by keratinocytes after UVB or Substance P stress.

Normal human keratinocyte secreted mediators were measured in the culture medium by ELISA (commercial kits). Data are expressed as a percentages of the control values. Statistic test for secretion's test: Analysis of variance, $\alpha=5 \% ; *$ : significative. $\mathrm{n}$ : number of experiments with keratinocytes from different donors (their response is expressed as an interval between minima and maxima).

nd : no determined 


\section{Keratinocyte treatment}

UVBs $10 \mathrm{~mJ} / \mathrm{cm}^{2}$ Substance P $10-7 M$

\section{Modulation of CEMT4 adhesion to HSkMEC (\%)}

\author{
minima
}

maxima

$\mathrm{n}$

$16.4 *$

$78.8 *$

4

$26.0 *$

Table 2 : Stimulation of CEMT4 leukocytes adhesion to skin endothelial cell by stressed keratinocyte-conditionned media.

Data are percentages of induction as compared to control values.

24 hours after EC contact with the keratinocyte-conditioned medium, FITC-labelled human leukocytes (CEMT4) were overlaid onto a PKH26-GL labelled human skin endothelial cells monolayer (HSkMEC.1) in a 5 to 1 ratio for a 20 min static adhesion at $37^{\circ} \mathrm{C}$. Quantification was done by flow cytometry assessment of the numbers of both cells .

Statistic test for adhesion's test : comparison of proportion following Normal Distribution, $\alpha=5 \% ; *$ : significative.

$\mathrm{n}$ : number of experiments with different donors (their response is translated as an interval between minima and maxima). 


\section{Figure Legends :}

Figure 1 : Protocol for measuring leukocyte adhesion to endothelial cells or keratinocytes.

A: Successive culture treatments and cell conditioning.

B: Quantification of the adhesion process by flow cytometry.

Lymphocytes are FL2 positive (upper left quadrant) and endothelial cells are non fluorescent, (lower left quadrant)

Figure 2 : UV effects on leukocyte recruitment in the skin as assessed by:

A. Modulation of skin endothelial cell adhesion capacity by conditioned medium from UV-induced keratinocytes and medium from cells treated with $\alpha-\mathrm{MSH}$. Activity assayed by the adhesion of CEMT4 lymphocyte cells measured by flow cytometry.

B. Modulation of keratinocyte adhesion capacity by UVB and blocking of the UVB action inhibition by $\alpha$-MSH. Assayed by CEMT4 lymphocyte cell adhesion estimated by flow cytometry.

CEMT4 cells labeled with PKH 26 were incubated for 20 min. at $37^{\circ} \mathrm{C}$ with ECs or a HAK monolayer, in a ratio of 5:1. Data are the numbers of CEMT4 per EC or HAK cell.

Figure 3 : Selective binding of CEMT4 leukocytes to endothelial cell lines. Modulation of the adhesion by keratinocyte-conditioned medium (treated with UVB, substance P or CGRP).

Figure 4 : Assessment of anti-inflammatory molecules by inhibition of the stress-induced adhesion of leukocytes to dermal endothelial cells via keratinocyte-conditioned medium.

Keratinocytes were stressed by UV irradiation or substance $\mathrm{P}$, and the stresses were modulated by anti-inflammatory molecules ( $\alpha-\mathrm{MSH}$, indomethacin, and dexamethasone). The anti-inflammatory effects were expressed as percentages of adhesion inhibition.

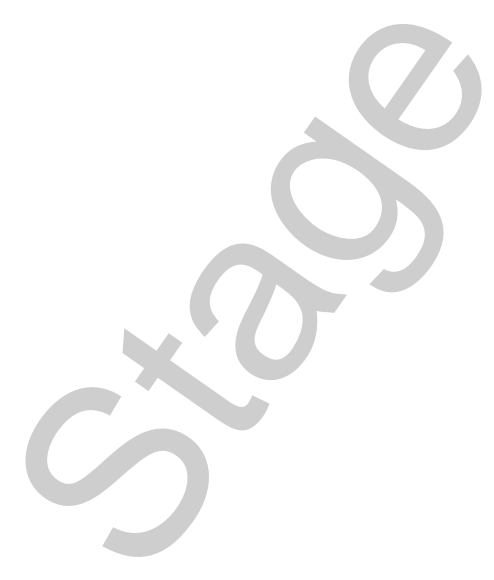


Figure $1 \mathrm{~A}$

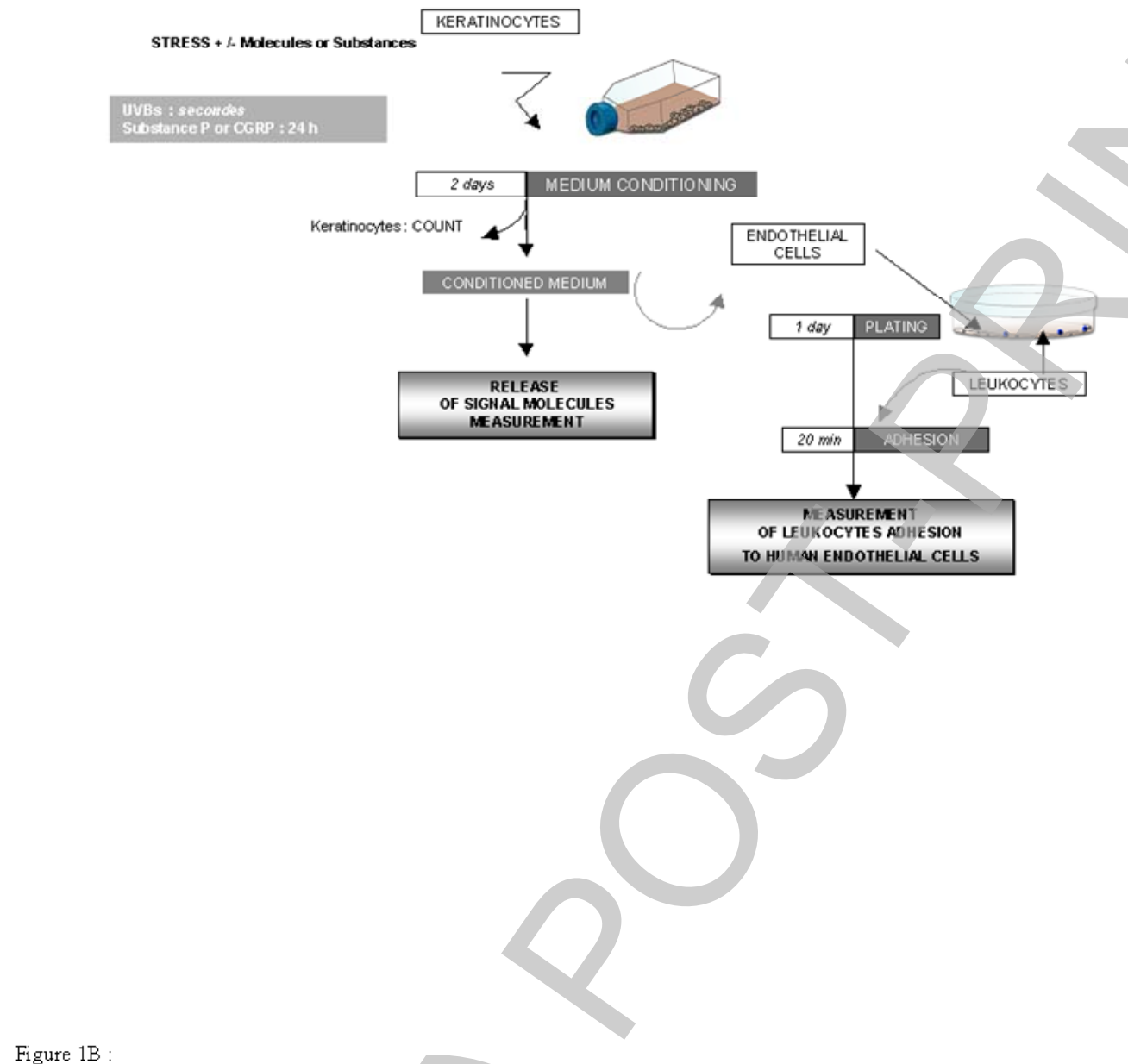

Flow cytometry analysis of the adhesion experiments

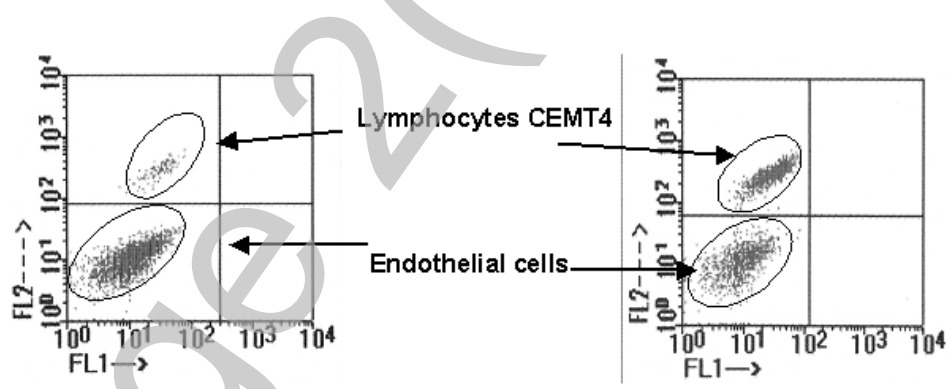

Before stress

After stress

Licenced copy. Copying is not permitted, except with prior permission and as allowed by law. (C) 2007 The Authors Journal compilation (C) 2007 Biochemical Society 
Figure $2 \mathrm{~A}$

Adhesion of Human Leukocytes to HSkMEC.1 (skin EC)

$\mathbb{N} \quad$ UVB + MSH $10^{-7} \mathrm{M}$

UVB

$\left(10 \mathrm{~mJ} / \mathrm{cm}^{2}\right)$

Control

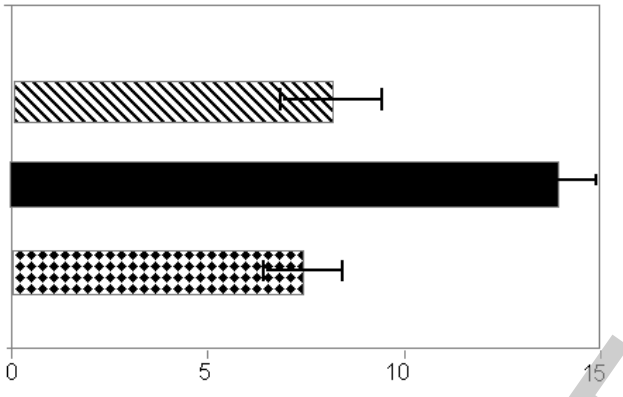

Leukocyte number / HSkMEC.1

Figure 2B

Adhesion of Human Leukocytes to Keratinocytes (HAK)

WVE $+M S H 10.7 \mathrm{M}$

UVB (10 m/icmen $)$

[i]

Control

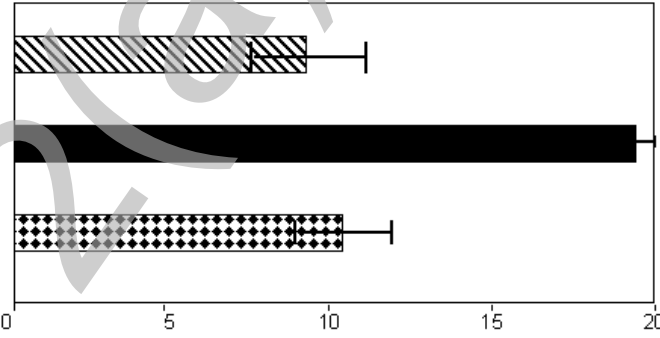

Leuk ocyte number / keratinocyte

Licenced copy. Copying is not permitted, except with prior permission and as allowed by law. (c) 2007 The Authors Journal compilation (c) 2007 Biochemical Society 
Figure 3:

Adhesion of Human Leukocytes to microcapillary ECs of different origins

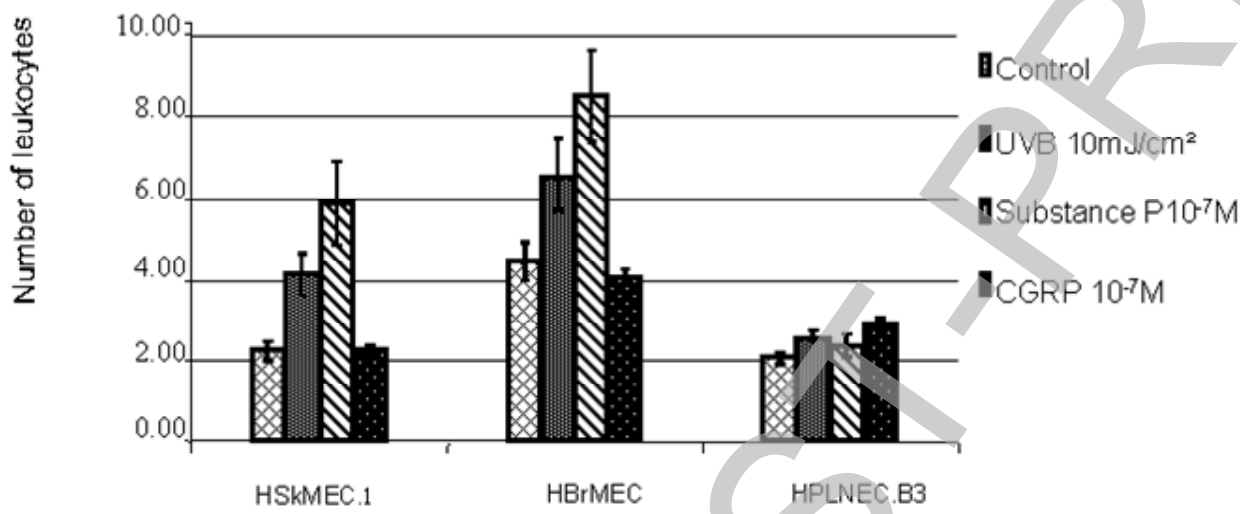


Figure 4

Anti-inflammatory molecules assessed by inhibition of dermal enclothelial celis adhesion activity towards CEMT4 induced by stressed keratinocytes medium

Stress applied

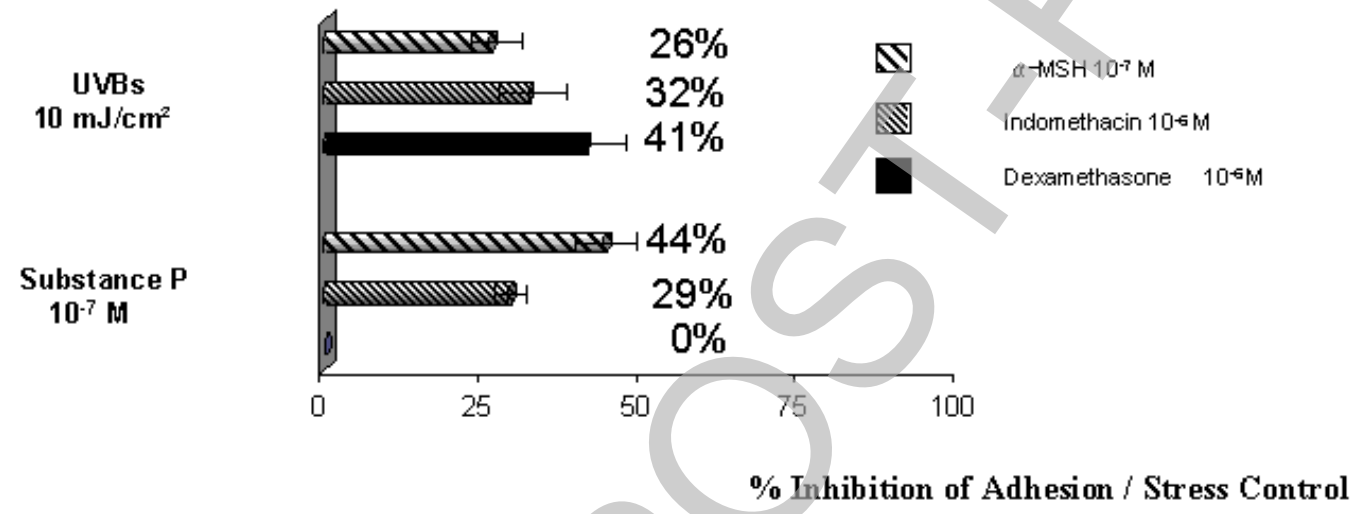

Licenced copy. Copying is not permitted, except with prior permission and as allowed by law.

(c) 2007 The Authors Journal compilation (c) 2007 Biochemical Society 


\section{References}

Akiba, H., Kehren, J., Ducluzeau, M.T., Krasteva, M., Horand, F., Kaiserlian, D., Kaneko, F. and Nicolas, J.F. (2002) Skin inflammation during contact hypersensitivity is mediated by early recruitment of CD8 $+\mathrm{T}$ cytotoxic 1 cells inducing keratinocyte apoptosis. $J$ Immunol, 168, 3079-3087.

Ansel, J.C., Armstrong, C.A., Song, I., Quinlan, K.L., Olerud, J.E., Caughman, S.W. and Bunnett, N.W. (1997) Interactions of the skin and nervous system. J Investig Dermatol Symp Proc, 2, 23-26.

Barker, J.N., Mitra, R.S., Griffiths, C.E., Dixit, V.M. and Nickoloff, B.J. (1991) Keratinocytes as initiators of inflammation. Lancet, 337, 211-214.

Berg, E.L., Yoshino, T., Rott, L.S., Robinson, M.K., Warnock, R.A., Kishimoto, T.K., Picker, L.J. and Butcher, E.C. (1991) The cutaneous lymphocyte antigen is a skin lymphocyte homing receptor for the vascular lectin endothelial cell-leukocyte adhesion molecule 1. J Exp Med, 174, 1461-1466.

Bevilacqua, M.P. (1993) Endothelial-leukocyte adhesion molecules. Annu Rev Immunol, 11, 767-804.

Bizouarne, N., Denis, V., Legrand, A., Monsigny, M. and Kieda, C. (1993a) A SV-40 immortalized murine endothelial cell line from peripheral lymph node high endothelium expresses a new alpha-L-fucose binding protein. Biol Cell, 79, 209-218.

Bizouarne, N., Mitterrand, M., Monsigny, M. and Kieda, C. (1993b) Characterization of membrane sugar-specific receptors in cultured high endothelial cells from mouse peripheral lymph nodes. Biol Cell, 79, 27-35.

Bosset, S., Bonnet-Duquennoy, M., Barre, P., Chalon, A., Kurfurst, R., Bonte, F., Schnebert, S., Le Varlet, B. and Nicolas, J.F. (2003) Photoageing shows histological features of chronic skin inflammation without clinical and molecular abnormalities. $\mathrm{Br} J$ Dermatol, 149, 826-835.

Boyce, S.T. and Ham, R.G. (1983) Calcium-regulated differentiation of normal human epidermal keratinocytes in chemically defined clonal culture and serum-free serial culture. J Invest Dermatol, 81, 33s-40s.

Bruynzeel, I., van der Raaij, L.M., Willemze, R. and Stoof, T.J. (1997) Pentoxifylline inhibits human T-cell adhesion to dermal endothelial cells. Arch Dermatol Res, 289, 189-193.

Butcher, E.C. and Picker, L.J. (1996) Lymphocyte homing and homeostasis. Science, 272, 6066.

Campbell, D.J. and Butcher, E.C. (2002) Rapid acquisition of tissue-specific homing phenotypes by CD4(+) T cells activated in cutaneous or mucosal lymphoid tissues. $J$ Exp Med, 195, 135-141.

Carlos, T.M. and Harlan, J.M. (1994) Leukocyte-endothelial adhesion molecules. Blood, 84, 2068-2101.

Chen, L., Lin, S.X., Agha-Majzoub, R., Overbergh, L., Mathieu, C. and Chan, L.S. (2006) CCL27 is a critical factor for the development of atopic dermatitis in the keratin-14 IL-4 transgenic mouse model. Int Immunol, 18, 1233-1242.

Choi, J.S., Choi, Y.J., Park, S.H., Kang, J.S. and Kang, Y.H. (2004) Flavones mitigate tumor necrosis factor-alpha-induced adhesion molecule upregulation in cultured human endothelial cells: role of nuclear factor-kappa B. J Nutr, 134, 1013-1019.

Chung, K.Y., Chang, N.S., Park, Y.K. and Lee, K.H. (2002) Effect of ultraviolet light on the expression of adhesion molecules and $\mathrm{T}$ lymphocyte adhesion to human dermal microvascular endothelial cells. Yonsei Med J, 43, 165-174.

Conway, K.P., Price, P., Harding, K.G. and Jiang, W.G. (2007) The role of vascular endothelial growth inhibitor in wound healing. Int Wound J, 4, 55-64. 
Daxecker, H., Raab, M., Markovic, S., Karimi, A., Griesmacher, A. and Mueller, M.M. (2002) Endothelial adhesion molecule expression in an in vitro model of inflammation. Clin Chim Acta, 325, 171-175.

Dus, D., Krawczenko, A., Zalecki, P., Paprocka, M., Wiedlocha, A., Goupille, C. and Kieda, C. (2003) IL-7 receptor is present on human microvascular endothelial cells. Immunol Lett, 86, 163-168.

Echigo, T., Hasegawa, M., Shimada, Y., Takehara, K. and Sato, S. (2004) Expression of fractalkine and its receptor, $\mathrm{CX} 3 \mathrm{CR} 1$, in atopic dermatitis: possible contribution to skin inflammation. J Allergy Clin Immunol, 113, 940-948.

Eves, P.C., MacNeil, S. and Haycock, J.W. (2006) alpha-Melanocyte stimulating hormone, inflammation and human melanoma. Peptides, 27, 444-452.

Fagerholm, S.C., Varis, M., Stefanidakis, M., Hilden, T.J. and Gahmberg, C.G. (2006) alphaChain phosphorylation of the human leukocyte CD11b/CD18 (Mac-1) integrin is pivotal for integrin activation to bind ICAMs and leukocyte extravasation. Blood, 108, 3379-3386.

Farkas, S., Hornung, M., Sattler, C., Edtinger, K., Steinbauer, M., Anthuber, M., Schlitt, H.J., Herfarth, H. and Geissler, E.K. (2006) Blocking MAdCAM-1 in vivo reduces leukocyte extravasation and reverses chronic inflammation in experimental colitis. Int J Colorectal Dis, 21, 71-78.

Frink, M., Hsieh, Y.C., Hsieh, C.H., Pape, H.C., Choudhry, M.A., Schwacha, M.G. and Chaudry, I.H. (2007) Keratinocyte-Derived Chemokine Plays a Critical Role in the Induction of Systemic Inflammation and Tissue Damage after Trauma-Hemorrhage. Shock, Publish Ahead of Print.

Giacomoni, P.U. and Rein, G. (2001) Factors of skin ageing share common mechanisms. Biogerontology, 2, 219-229.

Grandjean-Laquerriere, A., Le Naour, R., Gangloff, S.C. and Guenounou, M. (2003) Differential regulation of TNF-alpha, IL-6 and IL-10 in UVB-irradiated human keratinocytes via cyclic AMP/protein kinase A pathway. Cytokine, 23, 138-149.

Granger, D.N. and Kubes, P. (1994) The microcirculation and inflammation: modulation of leukocyte-endothelial cell adhesion. J Leukoc Biol, 55, 662-675.

Grone, A. (2002) Keratinocytes and cytokines. Vet Immunol Immunopathol, 88, 1-12.

Hase, T., Shinta, K., Murase, T., Tokimitsu, I., Hattori, M., Takimoto, R., Tsuboi, R. and Ogawa, H. (2000) Histological increase in inflammatory infiltrate in sun-exposed skin of female subjects: the possible involvement of matrix metalloproteinase-1 produced by inflammatory infiltrate on collagen degradation. Br J Dermatol, 142, 267-273.

Hasegawa, M., Sato, S., Echigo, T., Hamaguchi, Y., Yasui, M. and Takehara, K. (2005) Up regulated expression of fractalkine/CX3CL1 and CX3CR1 in patients with systemic sclerosis. Ann Rheum Dis, 64, 21-28.

Hayakawa, I., Hasegawa, M., Matsushita, T., Yanaba, K., Kodera, M., Komura, K., Takehara, K. and Sato, S. (2005) Increased cutaneous T-cell-attracting chemokine levels in sera from patients with systemic sclerosis. Rheumatology (Oxford), 44, 873-878.

Heck, D.E., Gerecke, D.R., Vetrano, A.M. and Laskin, J.D. (2004) Solar ultraviolet radiation as a trigger of cell signal transduction. Toxicol Appl Pharmacol, 195, 288-297.

Homey, B., Alenius, H., Muller, A., Soto, H., Bowman, E.P., Yuan, W., McEvoy, L., Lauerma, A.I., Assmann, T., Bunemann, E., Lehto, M., Wolff, H., Yen, D., Marxhausen, H., To, W., Sedgwick, J., Ruzicka, T., Lehmann, P. and Zlotnik, A. (2002) CCL27-CCR10 interactions regulate T cell-mediated skin inflammation. Nat Med, 8, 157-165.

Homey, B., Meller, S., Savinko, T., Alenius, H. and Lauerma, A. (2007) Modulation of chemokines by staphylococcal superantigen in atopic dermatitis. Chem Immunol Allergy, 93, 181-194. 
Hunger, R.E., Yawalkar, N., Braathen, L.R. and Brand, C.U. (1999) The HECA-452 epitope is highly expressed on lymph cells derived from human skin. Br J Dermatol, 141, 565569.

Igawa, K., Satoh, T., Hirashima, M. and Yokozeki, H. (2006) Regulatory mechanisms of galectin-9 and eotaxin-3 synthesis in epidermal keratinocytes: possible involvement of galectin-9 in dermal eosinophilia of Th1-polarized skin inflammation. Allergy, 61, 1385-1391.

Il'yasova, D., Colbert, L.H., Harris, T.B., Newman, A.B., Bauer, D.C., Satterfield, S. and Kritchevsky, S.B. (2005) Circulating levels of inflammatory markers and cancer risk in the health aging and body composition cohort. Cancer Epidemiol Biomarkers Prev, 14, 2413-2418.

Kieda, C. (2003) How endothelial cell organo-specificity mediates circulating cell homing. Arch Immunol Ther Exp (Warsz), 51, 81-89.

Kieda, C. and Dus, D. (2003) Endothelial cell glycosylation: regulation and modulation of biological processes. Adv Exp Med Biol, 535, 79-94.

Kieda, C., Paprocka, M., Krawczenko, A., Zalecki, P., Dupuis, P., Monsigny, M., Radzikowski, C. and Dus, D. (2002) New human microvascular endothelial cell lines with specific adhesion molecules phenotypes. Endothelium, 9, 247-261.

Kuijpers, T.W. and Roos, D. (1993) Leukocyte extravasation: mechanisms and consequences. Behring Inst Mitt, 107-137.

Kunkel, E. and Butcher, E. (2002) Homeostatic chemokines and the targeting of regional immunity. Adv Exp Med Biol, 512, 65-72.

Le, A.D., Zhang, Q., Wu, Y., Messadi, D.V., Akhondzadeh, A., Nguyen, A.L., Aghaloo, T.L., Kelly, A.P. and Bertolami, C.N. (2004) Elevated vascular endothelial growth factor in keloids: relevance to tissue fibrosis. Cells Tissues Organs, 176, 87-94.

Ley, K. (2003) Arrest chemokines. Microcirculation, 10, 289-295.

Li, J., Ireland, G.W., Farthing, P.M. and Thornhill, M.H. (1996) Epidermal and oral keratinocytes are induced to produce RANTES and IL-8 by cytokine stimulation. $J$ Invest Dermatol, 106, 661-666.

Lindsey, K.Q., Caughman, S.W., Olerud, J.E., Bunnett, N.W., Armstrong, C.A. and Ansel, J.C. (2000) Neural regulation of endothelial cell-mediated inflammation. J Investig Dermatol Symp Proc, 5, 74-78.

Luger, T.A., Scholzen, T., Brzoska, T., Becher, E., Slominski, A. and Paus, R. (1998) Cutaneous immunomodulation and coordination of skin stress responses by alphamelanocyte-stimulating hormone. Ann N Y Acad Sci, 840, 381-394.

Luger, T.A., Scholzen, T. and Grabbe, S. (1997) The role of alpha-melanocyte-stimulating hormone in cutaneous biology. J Investig Dermatol Symp Proc, 2, 87-93.

Luger, T.A., Scholzen, T.E., Brzoska, T. and Bohm, M. (2003) New insights into the functions of alpha-MSH and related peptides in the immune system. Ann N Y Acad Sci, 994, 133-140.

Luster, A.D. (1998) Chemokines--chemotactic cytokines that mediate inflammation. $N$ Engl $J$ Med, 338, 436-445.

Middleton, M.H. and Norris, D.A. (1995) Cytokine-induced ICAM-1 expression in human keratinocytes is highly variable in keratinocyte strains from different donors. $J$ Invest Dermatol, 104, 489-496.

Moed, H., Boorsma, D.M., Tensen, C.P., Flier, J., Jonker, M.J., Stoof, T.J., von Blomberg, B.M., Bruynzeel, D.P., Scheper, R.J., Rustemeyer, T. and Gibbs, S. (2004) Increased CCL27-CCR10 expression in allergic contact dermatitis: implications for local skin memory. J Pathol, 204, 39-46.

Nickoloff, B.J. (2006) Keratinocytes regain momentum as instigators of cutaneous inflammation. Trends Mol Med, 12, 102-106. 
Nishigori, C., Hattori, Y., Arima, Y. and Miyachi, Y. (2003) Photoaging and oxidative stress. Exp Dermatol, 12 Suppl 2, 18-21.

Oktar, B.K. and Alican, I. (2002) Modulation of the peripheral and central inflammatory responses by alpha-melanocyte stimulating hormone. Curr Protein Pept Sci, 3, 623628.

Park, L.J., Ju, S.M., Song, H.Y., Lee, J.A., Yang, M.Y., Kang, Y.H., Kwon, H.J., Kim, T.Y., Choi, S.Y. and Park, J. (2006) The enhanced monocyte adhesiveness after UVB exposure requires ROS and NF-kappaB signaling in human keratinocyte. J Biochem Mol Biol, 39, 618-625.

Pitzalis, C., Pipitone, N., Bajocchi, G., Hall, M., Goulding, N., Lee, A., Kingsley, G., Lanchbury, J. and Panayi, G. (1997) Corticosteroids inhibit lymphocyte binding to endothelium and intercellular adhesion: an additional mechanism for their antiinflammatory and immunosuppressive effect. J Immunol, 158, 5007-5016.

Purwar, R., Kraus, M., Werfel, T. and Wittmann, M. (2007) Modulation of KeratinocyteDerived MMP-9 by IL-13: A Possible Role for the Pathogenesis of Epidermal Inflammation. $J$ Invest Dermatol.

Schmuth, M., Watson, R.E., Deplewski, D., Dubrac, S., Zouboulis, C.C. and Griffiths, C.E. (2007) Nuclear hormone receptors in human skin. Horm Metab Res, 39, 96-105.

Scholzen, T.E., Brzoska, T., Kalden, D.H., O'Reilly, F., Armstrong, C.A., Luger, T.A. and Ansel, J.C. (1999) Effect of ultraviolet light on the release of neuropeptides and neuroendocrine hormones in the skin: mediators of photodermatitis and cutaneous inflammation. J Investig Dermatol Symp Proc, 4, 55-60.

Scholzen, T.E., Konig, S., Fastrich, M., Bohm, M. and Luger, T.A. (2007) Terminating the stress: peripheral peptidolysis of proopiomelanocortin-derived regulatory hormones by the dermal microvascular endothelial cell extracellular peptidases neprilysin and angiotensin-converting enzyme. Endocrinology, 148, 2793-2805.

Schon, M.P., Zollner, T.M. and Boehncke, W.H. (2003) The molecular basis of lymphocyte recruitment to the skin: clues for pathogenesis and selective therapies of inflammatory disorders. J Invest Dermatol, 121, 951-962.

Soter, N.A. (1990) Acute effects of ultraviolet radiation on the skin. Semin Dermatol, 9, 1115.

Springer, T.A. (1994) Traffic signals for lymphocyte recirculation and leukocyte emigration: the multistep paradigm. Cell, 76, 301-314.

Sugaya, M., Nakamura, K., Mitsui, H., Takekoshi, T., Saeki, H. and Tamaki, K. (2003) Human keratinocytes express fractalkine/CX3CL1. J Dermatol Sci, 31, 179-187.

Viac, J., Goujon, C., Misery, L., Staniek, V., Faure, M., Schmitt, D. and Claudy, A. (1997) Effect of UVB $311 \mathrm{~nm}$ irradiation on normal human skin. Photodermatol Photoimmunol Photomed, 13, 103-108.

von Andrian, U.H. and Mackay, C.R. (2000) T-cell function and migration. Two sides of the same coin. NEngl J Med, 343, 1020-1034.

Wagner, L.A. Brown, T., Gil, S., Frank, I., Carter, W., Tamura, R. and Wayner, E.A. (1999) The keratinocyte-derived cytokine IL-7 increases adhesion of the epidermal T cell subset to the skin basement membrane protein laminin-5. Eur J Immunol, 29, 25302538.

Wang, L., Eng, W. and Cockerell, C.J. (2002) Effects of ultraviolet irradiation on inflammation in the skin. Adv Dermatol, 18, 247-286.

Wilgus, T.A., Koki, A.T., Zweifel, B.S., Kusewitt, D.F., Rubal, P.A. and Oberyszyn, T.M. (2003) Inhibition of cutaneous ultraviolet light B-mediated inflammation and tumor formation with topical celecoxib treatment. Mol Carcinog, 38, 49-58.

Witkowska, A.M. and Borawska, M.H. (2004) Soluble intercellular adhesion molecule-1 (sICAM-1): an overview. Eur Cytokine Netw, 15, 91-98. 
Yuan, H., Goetz, D.J., Gaber, M.W., Issekutz, A.C., Merchant, T.E. and Kiani, M.F. (2005) Radiation-induced up-regulation of adhesion molecules in brain microvasculature and their modulation by dexamethasone. Radiat Res, 163, 544-551.

Zhang, W. and Chen, H. (2002) [The study on the interleukin-8 (IL-8)]. Sheng Wu Yi Xue Gong Cheng Xue Za Zhi, 19, 697-702. 